\title{
Effects of Naphthaleneacetic acid (NAA) on culm cuttings of Thyrsostachys siamensis Gamble
}

\author{
Cham V. Mac ${ }^{1 *}$, Thang V. Giang ${ }^{2}$, \& Ha V. H. La ${ }^{1}$ \\ ${ }^{1}$ Faculty of Forestry, Nong Lam University, Ho Chi Minh City, Vietnam \\ ${ }^{2}$ Forestry Science and Technology Association, Ho Chi Minh City, Vietnam
}

\section{ARTICLE INFO}

Research Paper

Received: May 07, 2018

Revised: June 28, 2018

Accepted: July 31, 2018

\section{Keywords}

Culm cuttings

Naphthaleneacetic acid (NAA)

Thyrsostachys siamensis Gamble

\section{${ }^{*}$ Corresponding author}

Mac Van Cham

Email: macvancham@hcmuaf.edu.vn

\begin{abstract}
The objective of this study was to evaluated the effects of Naphthaleneacetic acid (NAA) on shooting rate, number of shoots per cut, rooting rate, number of roots per cut by culm cuttings of Thyrsostachys siamensis Gamble. In the study, the bamboo samples were treated with NAA at different concentrations and time intervals. The experiment was designed in a randomized complete block of 2 factors with 17 treatments and 3 replications, with 36 culm cuts per treatment. The results showed that the treated groups with NAA had very high shooting rate, while the shooting rate of the control was relatively low. The concentration of NAA and soaking time significantly affected the shooting rate, number of shoots per cut, rooting rate, number of roots per cut. The interaction between NAA concentration and soaking time was significant. The result sugguest that soaking in NAA at the concentration of $200 \mathrm{ppm}$ and 120 minutes is the most appropriate treatment.
\end{abstract}

Cited as: Mac, C. V., Giang, T. V., \& La, H. V. H. (2019). Effects of Naphthaleneacetic acid (NAA) on culm cuttings of Thyrsostachys siamensis Gamble. The Journal of Agriculture and Development 18(1), 54-62. 


\title{
Ảnh hưởng của chất điều hòa sinh trưởng Naphthaleneacetic acid (NAA) đến khả năng giâm HOM thân tre Tầm vông Nam Bộ (Thyrsostachys siamensis Gamble)
}

\author{
Mạc Văn Chăm ${ }^{1 *}$, Giang Văn Thắng ${ }^{2} \&$ La Vĩnh Hải Hà ${ }^{1}$ \\ ${ }^{1}$ Khoa Lâm Nghiệp, Trường Đại Học Nông Lâm TP. Hồ Chí Minh, TP. Hồ Chí Minh \\ ${ }^{2}$ Hội Khoa Học Kỹ Thuật Lâm Nghiệp TP. Hồ Chí Minh, TP. Hồ Chí Minh
}

\section{THÔNG TIN BÀI BÁO}

\section{Bài báo khoa học}

Ngày nhận: 07/05/2018

Ngày chỉnh sửa: 28/06/2018

Ngày chấp nhận: 31/07/2018

\section{Từ khóa}

Giâm hom thân

Naphthaleneacetic acid (NAA)

Tre Tầm vông Nam Bộ

\section{*Tác giả liên hệ}

Mạc Văn Chăm

Email: macvancham@hcmuaf.edu.vn

\section{TÓM TẮT}

Bài báo này giới thiệu kết quả nghiên cứu về ảnh hưởng của chất điều hòa sinh trưởng (ĐHST) NAA đến tỷ lệ nảy chồi, số lượng chồi trên mỗi hom, tỷ lệ ra rễ và số rễ trên mỗi hom sau khi giâm hom thân tre Tầm vông Nam Bộ. Trong nghiên cứu này, chất điều hòa sinh trưởng NAA được sử dụng với 4 nồng độ và 4 khoảng thời gian ngâm. Thí nghiệm được bố trí theo kiểu khối đầy đủ ngẫu nhiên 2 nhân tố với 17 nghiệm thức (trong đó có 1 đối chứng) và 3 lần lặp lại, mỗi nghiệm thức của thí nghiệm có 36 hom. Kết quả cho thấy, các nghiệm thức có xử lý NAA cho tỷ lệ nảy chồi rất cao, trong khi nghiệm thức đối chứng (không xử lý NAA) cho tỷ lệ nảy chồi tương đối thấp. Ảnh hưởng của các yếu tố nồng độ và thời gian ngâm đến tỷ lệ nảy chồi, số lượng chồi, tỷ lệ ra rễ và số rễ trên mỗi hom của hom giâm là rõ rệt. Sự tương tác giữa nồng độ NAA và thời gian ngâm cũng ảnh hưởng rõ rệt đến tỷ lệ nảy chồi, tỷ lệ ra rễ và số lượng rễ trên mỗi hom nhưng không rõ rệt đối với số lượng chồi trên mỗi hom. Xử lý chất điều hòa sinh trưởng NAA với nồng độ 200 ppm và thời gian ngâm 120 phút là phù hợp nhất cho giâm hom thân tre Tầm vông Nam Bộ.

\section{1. Đặt Vấn Đề}

Tầm vông (Thyrsostachys siamensis Gamble) là một loài trong họ Tre trúc, phân bố tự nhiên rộng rãi ở dạng rừng thuần loài tại Myanma, Thái Lan. Tầm vông đã được trồng ở nhiều nước trong khu vực Đông Nam Á. Ở Việt Nam, cây Tầm vông được trồng chủ yếu ở các tỉnh phía Nam (Nguyen, 2005).

Theo trang báo Nông nghiệp Việt Nam (VAN, 2018), tình hình nguyên liệu gỗ hiện nay ngày một khan hiếm do việc đóng cửa rừng ở các nước, việc tìm những nguồn nguyên liệu khác để thay thế có thể đáp ứng không những về mặt nhu cầu mà còn đòi hỏi phải thỏa mãn yêu cầu ngày càng cao của xã hội. Để đáp ứng được nguồn nguyên liệu này, không thể không xuất phát từ nguồn cây giống và chăm sóc cây con trước khi trồng rừng cây tre trúc, trong đó có loài Tầm vông. Bên cạnh, theo Nguyen \& ctv. (2010), tình hình nghiên cứu về gây trồng Tầm vông cũng chỉ dừng lại ở giâm hom gốc và chiết cành. Để mở ra kỹ thuật nhân giống mới bằng phương pháp giâm hom thân thì việc xử lý các chất điều hòa sinh trưởng là rất cần thiết, bỡi lẽ ngoài khả năng sinh học của chúng, ta có thể chủ động kích thích bằng các chất điều hòa sinh trưởng với nồng độ và thời gian xử lý phù hợp, nhằm giúp cho các hom giâm điều chỉnh sự sinh trưởng của tế bào, hoạt động của tầng phát sinh, sự hình thành rễ... đem lại khả năng nảy chồi và ra rễ của hom giâm thân tre Tầm vông được tốt hơn.

Xuất phát từ vấn đề mang tính thực tế đó, việc nghiên cứu "ảnh hưởng của chất điều hòa sinh trưởng NAA đến khả năng giâm hom thân tre Tầm vông Nam Bộ (Thyrsostachys siamensis Gamble) được thực hiện nhằm tìm ra nồng độ và thời gian xử lý phù hợp với chất điều hoà sinh trưởng NAA để đem lại số lượng cây giống đạt chất lượng tốt trước khi đem trồng. 


\section{Vật Liệu và Phương Pháp Nghiên Cứu}

\subsection{Vật liệu nghiên cưu}

Các hom thân tre Tầm vông được lấy từ các vườn hộ của người dân tại thị xã Dĩ An, tỉnh Bình Dương đem về giâm ở vườn ươm tự tạo tại phường Tân Đông Hiệp, thị xã Dĩ An, tỉnh Bình Dương. Các cây lấy hom phải đảm bảo có cùng một giống (Tầm vông Nam Bộ).

\subsection{Phương pháp nghiên cứu}

\subsubsection{Công tác lấy giống}

Chọn những cây tre có thời gian khoảng 1 năm tuổi để tiến hành lấy giống. Cây được chọn là những cây sinh trưởng bình thường, không sâu bệnh, đường kính cây từ $3,5 \mathrm{~cm}$ trở lên.

Sau khi đã đánh dấu xong những cây được chọn, tiến hành chặt hạ cây, bảo quản và chở ngay về vườn ươm. Khi về đến vườn ươm tiến hành cưa thành những hom giống để đem ươm. Hom giống được cưa sao cho mắt tre nằm giữa hom. Chiều dài của các hom giống khoảng $25 \mathrm{~cm}$. Xử lý hom trước khi giâm: Hom sau khi đã cưa xong bỏ vào bồn để ngâm chất điều hòa sinh trưởng. NAA được pha ở các nồng độ 100 ppm, 200 ppm, $300 \mathrm{ppm}$ và $400 \mathrm{ppm}$. Tương ứng với mỗi nồng độ NAA, các hom được ngâm ở các khoảng thời gian khác nhau (60, 120, 180 và 240 phút).

\subsubsection{Chuẩn bị đất và giàn che}

Thực hiện làm đất trước khi giâm hom. Đất được cuốc tơi xốp, không còn cỏ dại. Trước khi giâm hom 1 tuần, tiến hành tưới thuốc để phòng trừ nấm. Làm thành từng luống (liếp) có chiều ngang khoảng 1 - 1,2 m. Phía bên trên dùng lưới có độ tàn che $50 \%$ để che mát cho chồi tre sau khi mọc.

\subsubsection{Giâm hom}

Hom sau khi đã ngâm chất điều hòa sinh trưởng, được đem ngay ra vườn để giâm. Để tiến hành giâm, dùng cuốc rạch thành từng rãnh nhỏ sâu khoảng $10 \mathrm{~cm}$. Bỏ hom xuống rãnh theo chiều nằm ngang, dùng tay ấn nhẹ để hom được nén chặt. Sau đó tiến hành lấp đất lại.

\subsubsection{Bố trí thí nghiệm}

Thí nghiệm được bố trí theo kiểu khối đầy đủ ngẫu nhiên 2 nhân tố với 3 lần lặp lại. Mỗi nghiệm thức được giâm 36 hom tre. Tổng cộng có 17 nghiệm thức: NT1 (100 ppm, 60 p), NT2 (200 ppm, 60 p), NT3 (300 ppm, 60 p), NT4 (400 ppm, 60 p), NT5 (100 ppm, 120 p), NT6 (200 ppm, 120 p), NT7 (300 ppm, 120 p), NT8 (400 ppm, 120 p), NT9 (100 ppm, 180 p), NT10 (200 ppm, 180 p), NT11 (300 ppm, 180 p), NT12 (400 ppm, 180 p), NT13 (100 ppm, 240 p), NT14 (200 ppm, 240 p), NT15 (300 ppm, 240 p), NT16 (400 ppm, 240 p) và NT17 (đối chứng).

Thời gian giâm hom được thực hiện vào mùa xuân (tháng $3-4$ trong năm).

\subsubsection{Thu thập số liệu}

- Các chỉ tiêu nghiên cứu được thu thập như sau:

Tỷ lệ hom nảy chồi (\%) và số lượng chồi (măng) trên mỗi hom: Xác định sau 21 ngày kể từ khi giâm.

Tỷ lệ hom ra rễ (\%) và số lượng rễ trên hom(rễ/hom): Xác định sau 75 ngày kể từ khi giâm.

\section{- Xử lý số liệu:}

Số liệu được xử lý theo phương pháp thống kê ứng dụng với sự trợ giúp của các phần mềm chuyên dụng trên máy vi tính: M. Excel 2010 và Statgraphics Centurion XV.I.

Trước hết, tính các đặc trưng thống kê mô tả (giá trị bình quân, độ lệch tiêu chuẩn... ) về tỷ lệ nảy chồi, số lượng chồi trên mỗi hom, tỷ lệ ra rễ và số lượng rễ trung bình trên mỗi hom.

Kế đến, tiến hành phân tích phương sai (ANOVA) và phân hạng (bằng trắc nghiệm Duncan) để so sánh giữa các nghiệm thức thí nghiệm bằng các chỉ tiêu đo đếm ở trên.

Tiếp theo, để tìm nồng độ $\mathrm{NAA}$ và thời gian xử lý tối ưu $(\mathrm{U})$ với từng chỉ tiêu, đã sử dụng phương pháp phân tích hồi quy và tương quan. Hàm hồi quy mô tả quan hệ giữa các biến phản hồi (tỷ lệ nảy chồi, số lượng chồi trên mỗi hom, tỷ lệ ra rễ và số lượng rễ trung bình trên mỗi hom) với yếu tố thí nghiệm (nồng độ NAA và thời gian xử lý) được xây dựng theo mô hình hồi quy đa thức bậc 2. Mô hình có dạng $\mathrm{Y}=\mathrm{b}_{0}+\mathrm{b}_{1} \times \mathrm{X}+\mathrm{b}_{2} \times \mathrm{X}^{2}$ $+\mathrm{e}$. Khi giải mô hình bậc 2 có thể xác định nồng độ NAA và thời gian xử lý tối ưu: $\mathrm{U}=-\mathrm{b}_{1} /(2 \times$ $\left.\mathrm{b}_{2}\right)$. 


\section{Kết Quả và Thảo Luận}

\subsection{Tỷ lệ nảy chồi}

Tỷ lệ nảy chồi và chồi tầm vông sau khi giâm hom được thể hiện ở Bảng 1 và Hình 1 .

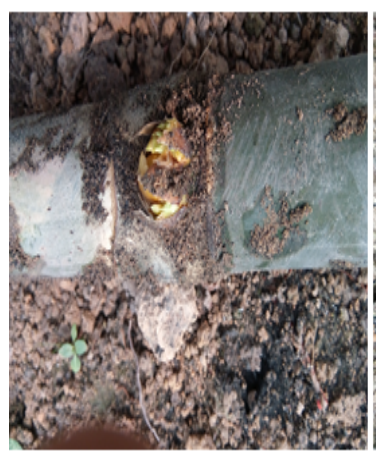

(a)

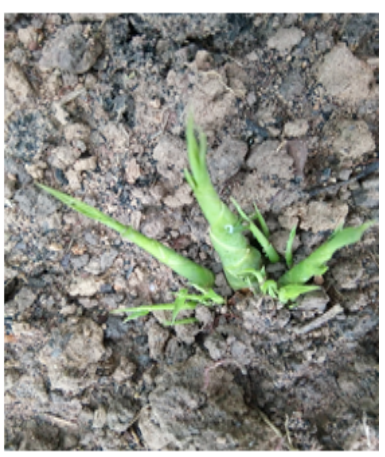

(b)
Hình 1. Chồi tầm vông sau khi giâm hom a) 3 ngày và b) 7 ngày.

Kết quả thí nghiệm cho thấy, tỷ lệ nảy chồi ở các nghiệm thức đều rất cao $(>76 \%)$. Trong khi đó, tỷ lệ nảy chồi của nghiệm thức đối chứng (không xử lý thuốc) chỉ đạt 51,9\%. Kết quả phân tích thống kê cho thấy nồng độ thuốc có ảnh hưởng rõ rệt đến tỷ lệ nảy chồi $(P<0,05)$. Bên cạnh đó, thời gian ngâm thuốc ảnh hưởng rất rõ rệt đến tỷ lệ nảy chồi $(P<0,01)$. Ảnh hưởng tương tác của nồng độ thuốc và thời gian ngâm đến tỷ lệ nảy chồi là rất rõ rệt $(P<0,01)$.

Kết quả sau khi phân tích hồi quy và tương quan (Hình 2 và 3 ) cho thấy, nồng độ NAA tối ưu cho tỷ lệ nảy chồi là $261 \mathrm{ppm}$ tương ứng với tỷ lệ này chồi cao nhất là $94,46 \%$ và thời gian xử lý tối ưu cho tỷ lệ nảy chồi là 161 phút tương ứng với tỷ lệ nảy chồi cao nhất là 94,44\%.

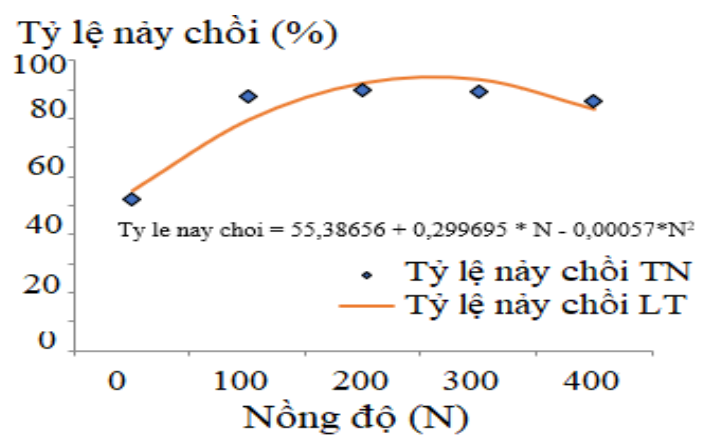

Hình 2. Tỷ lệ nảy chồi $(\%)$ của hom ở các nồng độ NAA khác nhau.

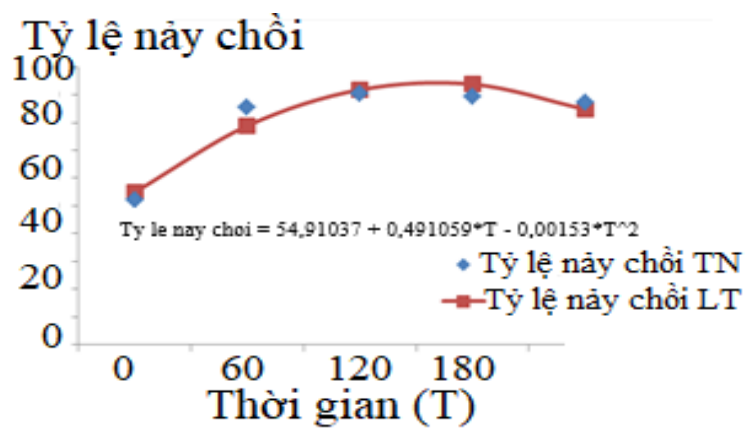

Hình 3. Tỷ lệ nảy chồi $(\%)$ của hom ở các khoảng thời gian xử lý NAA khác nhau.

Kết quả Bảng 2 cho thấy, các nghiệm thức được phân thành 6 nhóm (các nghiệm thức nằm cùng 1 nhóm thì sự sai khác về tỷ lệ nảy chồi giữa chúng là không có ý nghĩa) với giá trị từ thấp đến cao. Nhóm có tỷ lệ nảy chồi cao nhất là nhóm gồm có 11 nghiệm thức lần lượt là: $6,5,10,3,9,13,4$, $11,14,7$ và 15 . Trong đó, nghiệm thức 6 với nồng độ NAA là 200 ppm và thời gian ngâm thuốc là 120 phút cho tỷ lệ nảy chồi là cao hơn so với 10 nghiệm thức còn lại trong nhóm.

\subsection{Số lượng chồi trên mỗi hom}

Kết quả thí nghiệm sau khi tổng hợp được thể hiện ở Bảng 3.

Kết quả sau khi phân tích thống kê cho thấy, nồng độ và thời gian ngâm thuốc có ảnh hưởng đến số lượng chồi trung bình trên mỗi hom $(P<$ $0,05)$. Tuy nhiên, ảnh hưởng tương tác của nồng độ và thời gian ngâm thuốc đến số lượng chồi trung bình trên mỗi hom là không rõ rệt $(P>$ $0,05)$.

Kết quả sau khi phân tích hồi quy và tương quan (Hình 4 và 5 ) cho thấy, nồng độ NAA tối ưu cho số chồi trên mỗi hom là 203 ppm tương ứng với số chồi cao nhất là 3,33 chồi/hom và thời gian xử lý tối ưu cho số chồi trên mỗi hom là 127 phút tương ứng với số chồi cao nhất là 3,33 chồi/hom.

Kết quả sau khi phân tích thống kê (Bảng 4) cho thấy, các nghiệm thức được phân thành 3 nhóm với giá trị từ thấp đến cao. Nhóm có số lượng chồi trung bình trên mỗi hom cao nhất là nhóm gồm có 8 nghiệm thức lần lượt là: $6,5,2,9$, $10,4,13$ và 7 . Trong đó, nghiệm thức 6 với nồng độ 200 ppm và thời gian ngâm 120 phút cho số lượng chồi trung bình trên mỗi hom là cao nhất. 
Bảng 1. Tỷ lệ nảy chồi $(\%)$ của hom tre sau khi xử lý NAA

\begin{tabular}{|c|c|c|c|c|c|}
\hline \multirow{2}{*}{$\begin{array}{c}\text { Nồng độ }(\mathrm{N}) \\
(\mathrm{ppm})\end{array}$} & \multicolumn{4}{|c|}{ Thời gian ngâm thuốc (T) (phút) } & \multirow{2}{*}{ Trung bình } \\
\hline & 60 & 120 & 180 & 240 & \\
\hline Đối chứng & \multicolumn{4}{|c|}{$51,9 \pm 1,85$} & \\
\hline 100 & $76,9 \pm 2,45$ & $91,7 \pm 1,60$ & $90,7 \pm 2,45$ & $90,7 \pm 1,85$ & 87,5 \\
\hline 200 & $84,3 \pm 2,45$ & $93,5 \pm 0,93$ & $90,7 \pm 0,93$ & $89,8 \pm 2,45$ & 89,6 \\
\hline 300 & $90,7 \pm 0,93$ & $88,9 \pm 1,60$ & $89,8 \pm 1,85$ & $88,0 \pm 2,45$ & 89,4 \\
\hline 400 & $89,8 \pm 0,93$ & $87,0 \pm 1,85$ & $86,1 \pm 1,60$ & $80,6 \pm 1,60$ & 85,9 \\
\hline Trung bình & 85,4 & 90,3 & 89,4 & 87,3 & \\
\hline & $\mathrm{P}_{\mathrm{N}}=0,01$ & $\mathrm{P}_{\mathrm{T}}=0,00$ & $\mathrm{P}_{\mathrm{NT}}=0,00$ & & \\
\hline
\end{tabular}

Bảng 2. Kết quả phân hạng của các nghiệm thức tới tỷ lệ nảy chồi với trắc nghiệm Duncan

\begin{tabular}{cccc}
\hline Nghiệm thức & Số lượng & Trung bình & Phân hạng \\
\hline 17 & 3 & 51,86 & a \\
1 & 3 & 76,85 & b \\
16 & 3 & 80,56 & c \\
2 & 3 & 84,26 & cd \\
12 & 3 & 86,10 & de \\
8 & 3 & 87,03 & de \\
15 & 3 & 87,96 & def \\
7 & 3 & 88,90 & def \\
14 & 3 & 89,80 & def \\
11 & 3 & 89,83 & def \\
4 & 3 & 89,83 & def \\
13 & 3 & 90,73 & ef \\
9 & 3 & 90,73 & ef \\
3 & 3 & 90,76 & ef \\
10 & 3 & 90,76 & ef \\
5 & 3 & 91,66 & ef \\
6 & 3 & 93,50 & f \\
\hline
\end{tabular}

Bảng 3. Số lượng chồi trung bình trên mỗi hom tre sau khi xử lý NAA

\begin{tabular}{|c|c|c|c|c|c|}
\hline \multirow{2}{*}{$\begin{array}{l}\text { Nồng độ }(\mathrm{N}) \\
\text { (ppm) }\end{array}$} & \multicolumn{4}{|c|}{ Thời gian ngâm thuốc $(\mathrm{T})$ (phút) } & \multirow{2}{*}{ Trung bình } \\
\hline & 60 & 120 & 180 & 240 & \\
\hline Đối chứng & \multicolumn{4}{|c|}{$3,2 \pm 0,16$} & \\
\hline 100 & $3,24 \pm 0,12$ & $3,37 \pm 0,09$ & $3,32 \pm 0,10$ & $3,30 \pm 0,09$ & 3,31 \\
\hline 200 & $3,33 \pm 0,12$ & $3,47 \pm 0,10$ & $3,32 \pm 0,09$ & $3,28 \pm 0,10$ & 3,35 \\
\hline 300 & $3,28 \pm 0,11$ & $3,29 \pm 0,09$ & $3,27 \pm 0,09$ & $3,27 \pm 0,10$ & 3,28 \\
\hline 400 & $3,30 \pm 0,11$ & $3,27 \pm 0,09$ & $3,24 \pm 0,11$ & $3,09 \pm 0,11$ & 3,22 \\
\hline \multirow[t]{2}{*}{ Trung bình } & 3,29 & 3,35 & 3,28 & 3,24 & \\
\hline & $\mathrm{P}_{\mathrm{N}}=0,02$ & $\mathrm{P}_{\mathrm{T}}=0,04$ & $\mathrm{P}_{\mathrm{NT}}=0,39$ & & \\
\hline
\end{tabular}

\subsection{Tỷ lệ ra rễ}

Kết quả thí nghiệm sau khi tổng hợp được thể hiện ở Bảng 5 .

Kết quả phân tích thống kê cho thấy, ảnh hưởng của các yếu tố nồng độ NAA và thời gian ngâm đến khả năng ra rễ của cây tre Tầm vông
Nam Bộ giâm hom là rất có ý nghĩa về mặt thống kê (với $P<0,01$ ), Ngoài ra, sự tương tác của 2 yếu tố này đến khả năng ra rễ là rất rõ rệt $(P<$ $0,01)$.

Kết quả sau khi phân tích hồi quy và tương quan (Hình 6 và 7 ) cho thấy, nồng độ NAA tối ưu cho tỷ lệ ra rễ là 240 ppm tương ứng với tỷ lệ 
Bảng 4. Kết quả phân hạng của các nghiệm thức tới số lượng chồi trung bình trên mỗi hom với trắc nghiệm Duncan

\begin{tabular}{cccc}
\hline Nghiệm thức & Số lượng & Trung bình & Phân hạng \\
\hline 16 & 3 & 3,09 & $\mathrm{a}$ \\
17 & 3 & 3,19 & $\mathrm{ab}$ \\
1 & 3 & 3,23 & $\mathrm{ab}$ \\
12 & 3 & 3,24 & $\mathrm{ab}$ \\
8 & 3 & 3,26 & $\mathrm{ab}$ \\
11 & 3 & 3,26 & $\mathrm{ab}$ \\
15 & 3 & 3,27 & $\mathrm{~b}$ \\
3 & 3 & 3,27 & $\mathrm{~b}$ \\
14 & 3 & 3,28 & $\mathrm{~b}$ \\
7 & 3 & 3,29 & $\mathrm{bc}$ \\
13 & 3 & 3,29 & $\mathrm{bc}$ \\
4 & 3 & 3,29 & $\mathrm{bc}$ \\
10 & 3 & 3,31 & $\mathrm{bc}$ \\
9 & 3 & 3,31 & $\mathrm{bc}$ \\
2 & 3 & 3,32 & $\mathrm{bc}$ \\
5 & 3 & 3,37 & $\mathrm{bc}$ \\
6 & 3 & 3,46 & $\mathrm{c}$ \\
\hline
\end{tabular}

Bảng 5. Tỷ lệ ra rễ (\%) của hom tre sau khi xử lý NAA

\begin{tabular}{|c|c|c|c|c|c|}
\hline \multirow{2}{*}{$\begin{array}{c}\text { Nồng độ }(\mathrm{N}) \\
(\mathrm{ppm})\end{array}$} & \multicolumn{4}{|c|}{ Thời gian ngâm thuốc (T) (phút) } & \multirow{2}{*}{ Trung bình } \\
\hline & 60 & 120 & 180 & 240 & \\
\hline Đối chứng & \multicolumn{4}{|c|}{$1,85 \pm 0,92$} & \\
\hline 100 & $73,15 \pm 1,85$ & $79,63 \pm 1,60$ & $83,33 \pm 4,03$ & $78,70 \pm 1,60$ & 81,71 \\
\hline 200 & $86,11 \pm 3,34$ & $87,96 \pm 0,93$ & $80,56 \pm 0,93$ & $60,19 \pm 2,45$ & 83,33 \\
\hline 300 & $84,26 \pm 1,60$ & $84,26 \pm 1,60$ & $78,70 \pm 2,45$ & $57,41 \pm 3,21$ & 76,62 \\
\hline 400 & $83,33 \pm 2,45$ & $81,48 \pm 2,45$ & $63,89 \pm 2,45$ & $49,07 \pm 3,34$ & 61,34 \\
\hline \multirow[t]{2}{*}{ Trung bình } & 78,70 & 78,70 & 76,16 & 69,44 & \\
\hline & $\mathrm{P}_{\mathrm{N}}=0,00$ & $\mathrm{P}_{\mathrm{T}}=0,00$ & $\mathrm{P}_{\mathrm{NT}}=0,00$ & & \\
\hline
\end{tabular}

\section{Số lượng chồi}

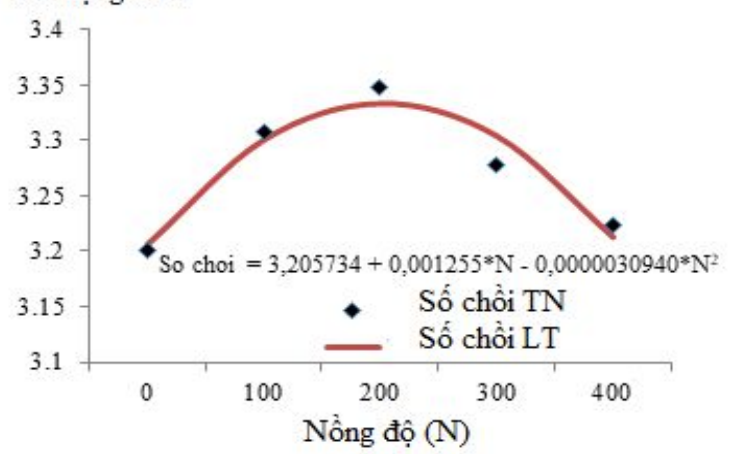

Hình 4. Số lượng chồi (chồi/hom) của hom ở các nồng độ NAA khác nhau.

ra rễ cao nhất là $91,6 \%$ và thời gian xử lý tối ưu cho tỷ lệ ra rễ là 153 phút tương ứng với tỷ lệ ra rễ cao nhất là $88,84 \%$.

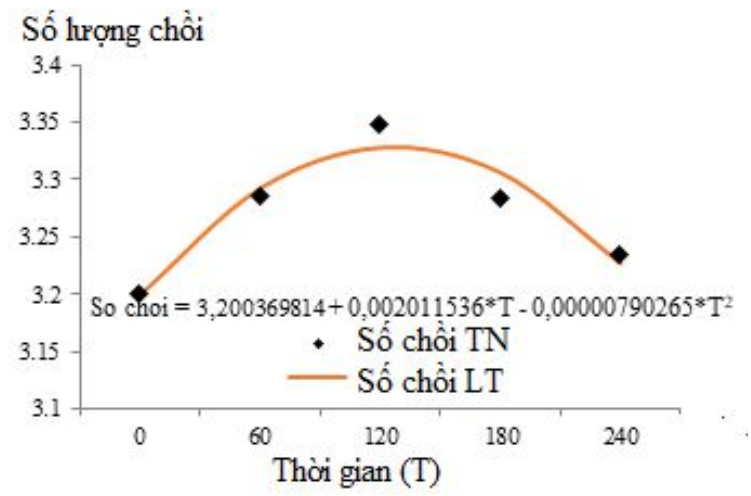

Hình 5. Số lượng chồi (chồi/hom) của hom ở các khoảng thời gian xử lý NAA khác nhau.

Kết quả Bảng 6 cho thấy, các nghiệm thức được phân thành 8 nhóm với giá trị từ thấp đến cao. Nhóm có tỷ lệ ra rễ cao nhất là nhóm gồm có 


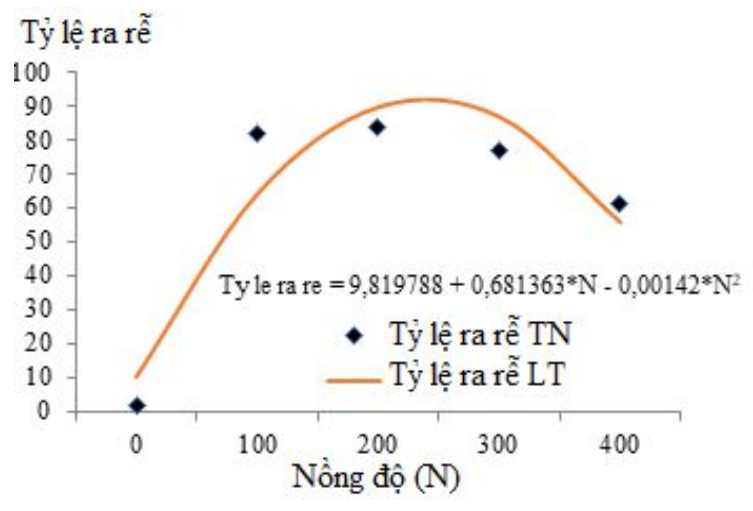

Hình 6. Tỷ lệ ra rễ (\%) của hom ở các nồng độ NAA khác nhau.

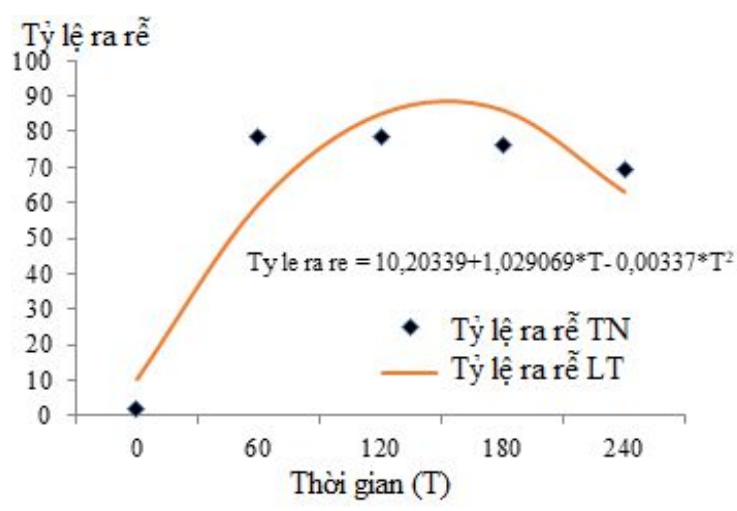

Hình 7. Tỷ lệ ra rễ (\%) của hom ở các hoảng thời gian xử lý NAA khác nhau.

7 nghiệm thức lần lượt là: $6,5,9,10,3,13$ và 14. Trong đó, nghiệm thức thứ 6 với nồng độ 200 ppm và thời gian ngâm thuốc 120 phút cho tỷ lệ ra rễ là cao nhất, kế đến là nghiệm thức 5 với nồng độ là 100 ppm và thời gian ngâm thuốc là 120 phút.

\subsection{Số rễ trên hom}

Kết quả thí nghiệm sau khi tổng hợp được thể hiện ở Bảng 7.

Kết quả phân tích thống kê cho thấy, ảnh hưởng của các yếu tố nồng độ NAA và thời gian ngâm đến số lượng rễ trên mỗi hom của cây tre Tầm vông Nam Bộ giâm hom là rất có ý nghĩa về mặt thống kê $(P<0,01)$, Ngoài ra, sự tương tác của 2 yếu tố này đến số lượng rễ trên hom là rất rõ rệt $(P<0,01)$.

Kết quả sau khi phân tích hồi quy và tương quan (Hình 8 và 9 ) cho thấy, nồng độ NAA tối ưu cho số lượng rễ trên hom là 218 ppm tương ứng với số lượng rễ cao nhất là 8,1 rễ/hom và thời gian xử lý tối ưu cho số lượng rễ trên hom là 148 phút tương ứng với số lượng rễ cao nhất là 7,8 rễ/hom.

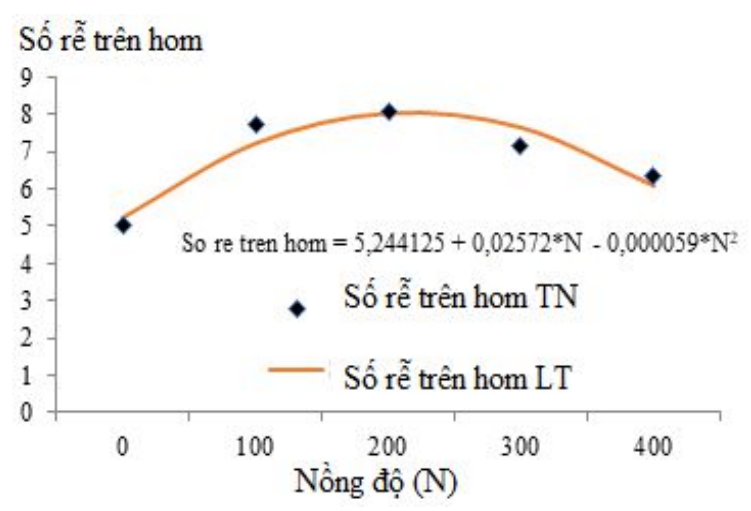

Hình 8. Số rễ trên hom ở các nồng độ NAA khác nhau.

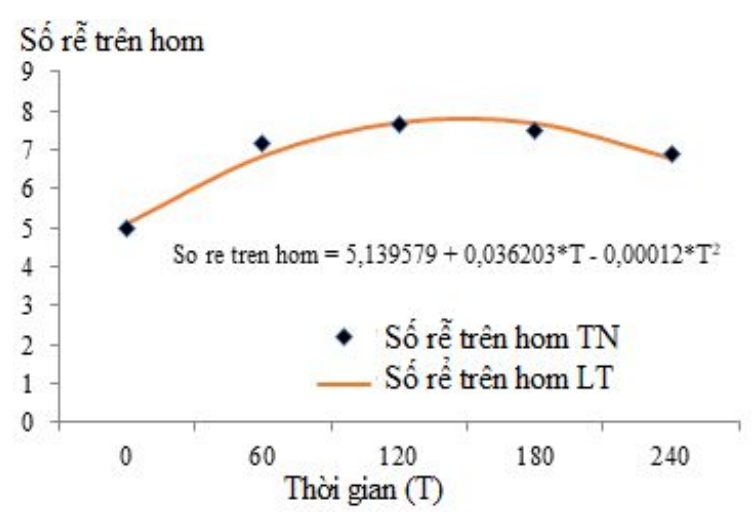

Hình 9. Số rễ trên hom ở các khoảng thời gian xử lý NAA khác nhau.

Kết quả Bảng 8 cho thấy, các nghiệm thức được phân thành 7 nhóm với giá trị từ thấp đến cao. Nhóm có tỷ lệ ra rễ cao nhất là nhóm gồm có 4 nghiệm thức lần lượt là: $6,5,10$ và 9 . Trong đó, nghiệm thức thứ 6 với nồng độ 200 ppm và thời gian ngâm thuốc 120 phút cho tỷ lệ ra rễ là cao nhất, kế đến là nghiệm thức 5 với nồng độ là 100 ppm và thời gian ngâm thuốc là 120 phút.

\subsection{Thảo luận}

Nhìn chung, có sự ảnh hưởng của chất điều hòa sinh trưởng NAA đến giâm hom thân tre Tầm vông Nam Bộ. Kết quả phân tích cho thấy, nồng độ NAA tối ưu cho tỷ lệ nảy chồi, số lượng chồi trên hom, tỷ lệ ra rễ và số rễ trên mỗi hom dao 
Bảng 6. Kết quả phân hạng của các nghiệm thức tới tỷ lệ ra rễ của hom tre với trắc nghiệm Duncan

\begin{tabular}{cccc}
\hline Nghiệm thức & Số lượng & Trung bình & Phân hạng \\
\hline 17 & 3 & 1,85 & $\mathrm{a}$ \\
16 & 3 & 49,07 & $\mathrm{~b}$ \\
12 & 3 & 57,40 & $\mathrm{c}$ \\
8 & 3 & 60,18 & cd \\
15 & 3 & 63,88 & d \\
1 & 3 & 73,14 & e \\
11 & 3 & 78,70 & ef \\
4 & 3 & 78,70 & ef \\
2 & 3 & 79,63 & fg \\
7 & 3 & 80,55 & fg \\
14 & 3 & 81,48 & fgh \\
13 & 3 & 83,33 & fgh \\
3 & 3 & 83,33 & fgh \\
10 & 3 & 84,25 & fgh \\
9 & 3 & 84,26 & fgh \\
5 & 3 & 86,11 & gh \\
6 & 3 & 87,96 & h \\
\hline
\end{tabular}

Bảng 7. Số rễ trên hom của hom tre sau khi xử lý NAA

\begin{tabular}{cccccc}
\hline \multirow{2}{*}{$\begin{array}{c}\text { Nồng độ }(\mathrm{N}) \\
\text { (ppm) }\end{array}$} & 60 & \multicolumn{5}{c}{ Thời gian ngâm thuốc (T) (phút) } & \multirow{2}{*}{ Trung bình } \\
\cline { 2 - 5 } & \multicolumn{5}{c}{$5,0 \pm 1,0$} \\
\hline Đối chứng & $6,31 \pm 0,25$ & $8,44 \pm 0,37$ & $8,20 \pm 0,37$ & $7,87 \pm 0,37$ & 7,70 \\
100 & $7,53 \pm 0,39$ & $8,69 \pm 0,44$ & $8,38 \pm 0,41$ & $7,65 \pm 0,37$ & 8,06 \\
200 & $7,73+0,41$ & $7,32 \pm 0,39$ & $7,21 \pm 0,39$ & $6,27 \pm 0,31$ & 7,13 \\
300 & $7,14 \pm 0,31$ & $6,19 \pm 0,29$ & $6,19 \pm 0,32$ & $5,89 \pm 0,32$ & 6,35 \\
400 & 7,18 & 7,66 & 7,50 & 6,92 \\
Trung bình & $\mathrm{P}_{\mathrm{N}}=0,00$ & $\mathrm{P}_{\mathrm{T}}=0,00$ & $\mathrm{P}_{\mathrm{NT}}=0,00$ \\
\hline \multicolumn{5}{c}{}
\end{tabular}

Bảng 8. Kết quả phân hạng của các nghiệm thức tới số lượng rễ trên hom của hom tre với trắc nghiệm Duncan

\begin{tabular}{cccc}
\hline Nghiệm thức & Số lượng & Trung bình & Phân hạng \\
\hline 17 & 3 & 5,0 & $\mathrm{a}$ \\
16 & 3 & 5,9 & $\mathrm{~b}$ \\
8 & 3 & 6,2 & $\mathrm{~b}$ \\
12 & 3 & 6,2 & $\mathrm{~b}$ \\
15 & 3 & 6,3 & $\mathrm{~b}$ \\
1 & 3 & 6,3 & $\mathrm{~b}$ \\
4 & 3 & 7,1 & $\mathrm{c}$ \\
11 & 3 & 7,2 & $\mathrm{c}$ \\
7 & 3 & 7,3 & $\mathrm{~cd}$ \\
2 & 3 & 7,5 & $\mathrm{~cd}$ \\
14 & 3 & 7,7 & $\mathrm{cde}$ \\
3 & 3 & 7,7 & $\mathrm{cde}$ \\
13 & 3 & 7,9 & def \\
9 & 3 & 8,2 & efg \\
10 & 3 & 8,4 & fg \\
5 & 3 & 8,4 & fg \\
6 & 3 & 8,7 & $\mathrm{~g}$ \\
\hline
\end{tabular}


động trong khoảng 203 ppm đến 261 ppm. Kết quả này có phần cao hơn so với Ngo (2003) khi nghiên cứu giâm hom thân cho cây Tre gai với nồng độ 50 - 150 ppm bằng các chất điều hòa sinh trưởng NAA, IBA và $\mathrm{ABT}$. Thời gian xử lý NAA tối ưu cho tỷ lệ nảy chồi, số lượng chồi trên hom, tỷ lệ ra rễ và số rễ trên mỗi hom dao động trong khoảng 127 phút đến 161 phút.

Kết quả phân hạng cũng cho thấy, giữa các chỉ tiêu xem xét thì các nghiệm thức đạt trung bình cao nhất ở nhóm thuần nhất không hoàn toàn trùng nhau, tuy nhiên các nghiệm thức $5,6,9$ và 10 luôn luôn xuất hiện trong nhóm cao nhất. Trong đó, 2 nghiệm thức 6 và 5 luôn cho kết quả về tỷ lệ nảy chồi, số lượng chồi trên hom, tỷ lệ ra rễ và số rễ trên mỗi hom cao nhất và nhì trong nhóm. Kết quả này cũng tương đồng với kết quả nghiên cứu của Mac \& ctv. (2013) về tỷ lệ ra rễ của hom tre Tầm vông khi xử lý bằng chất điều hòa sinh trưởng IBA.

Căn cứ vào kết quả phân nhóm qua Duncan, hai chỉ tiêu tỷ lệ ra rễ và số rễ trên hom phân hoá thành nhiều nhóm thuần nhất hơn so với hai chỉ tiêu tỷ lệ nảy chồi và số lượng chồi trên mỗi hom, chứng tỏ chúng nhạy bén hơn với thay dổi của nồng độ hoặc thời gian khi xử lý bởi NAA.

\section{Kết Luận}

Việc nhân giống tre Tầm vông Nam Bộ bằng phương pháp giâm hom thân đã đem lại kết quả khả quan khi sử dụng chất điều hòa sinh trưởng NAA với nồng độ và thời gian thích hợp.

Khi có sử dụng chất điều hòa sinh trưởng NAA thì các hom thân tre Tầm vông cho tỷ lệ nảy chồi khá cao (> 76\%). Từng yếu tố nồng độ NAA hoặc thời gian ngâm có ảnh hưởng rõ rệt đến các chỉ tiêu tỷ lệ nảy chồi, số lượng chồi, tỷ lệ ra rễ và số rễ trên mỗi hom. Sự tương tác giữa nồng độ NAA và thời gian ngâm ảnh hưởng rõ rệt đến tỷ lệ nảy chồi, tỷ lệ ra rễ và số rễ trên mỗi hom. Nồng độ NAA và thời gian xử lý tối ưu cho các chỉ tiêu dao động trong khoảng 203 - 261 ppm và 127 161 phút.

Các nghiệm thức xử lý cho giâm hom thân cây tre Tầm vông nên chọn theo thứ tự ưu tiên là NT6 (200 ppm, 120 p), NT5 (100 ppm, 120 p), NT9 (100 ppm, 180 p) và NT10 (200 ppm, 180 p).

\section{Tài Liệu Tham Khảo (References)}

Mac, C. V., Ngo, D. Q., Tang, H. T. K., \& Ho, D. T. T. (2013). Breeding nulgar bamboo (Thyrsostachys siamensis Gamble) by cultivating the cutting segments. Journal of Agricultural Science and Technology 3, 7780.

Ngo, D. Q. (2003). Bamboo (planting and utilization). Nghe An, Vietnam: Nghe An Publising House.

Nguyen, K. D., Nguyen, H. Q., Luu, T. Q., \& Do, B. V. (2010). Breeding techniques thyrsostachys siamensis (Kurz ex Munro) gamble and bambusa spp. By rhizomes and brach air-layering. Journal of Forest Science $4,12-16$.

Nguyen, N. H. (2005). Vietnam Bamboo. Ha Noi, Vietnam: Agricultural Publishing House.

VAN (Vietnam Agriculture Newspaper). Wood industry faces difficulties in raw materials. (2018). Retrieved March 23, 2018, from https://nongnghiep.vn/nganhgo-gap-kho-ve-go-nguyen-lieu-post204200.html. 